\title{
Vesicoenteric Fistula Arising from an Adenocarcinoma of Ectopic Pancreatic Tissue in a Meckel Diverticulum
}

\author{
Naoyuki Fujita ${ }^{a}$ Mitsuhiro Tambo $^{a}$ Yuichi Terado $^{b} \quad$ Michio Fujita $^{c}$

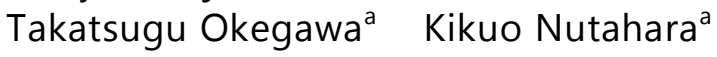 \\ ${ }^{a}$ Department of Urology, Kyorin University School of Medicine, Mitaka, Japan; \\ ${ }^{b}$ Department of Pathology, Kawasaki Saiwai Hospital, Kawasaki, Japan; ' Department of \\ Urology, Fujita Clinic, Funabashi, Japan
}

\section{Keywords}

Meckel diverticulum · Vesicoenteric fistula - Ectopic pancreas

\begin{abstract}
We report a case of a vesicoenteric fistula arising from an adenocarcinoma of ectopic pancreatic tissue in a Meckel diverticulum in a 58-year-old man. The patient suffered from refractory micturition pain and increased urinary frequency. Computerized tomography with a contrast agent showed a ring-shaped enhanced mass near the dome of the urinary bladder. Magnetic resonance imaging showed a cystic mass close to the urinary bladder with partly irregular wall and fistula formation to the urinary bladder. Surgical findings showed a Meckel diverticulum in the ileum, which formed a fistula with the urinary bladder, and Meckel diverticulectomy and partial cystectomy were performed. Histological findings revealed a vesicoenteric fistula arising from a papillary adenocarcinoma of ectopic pancreatic tissue in a Meckel diverticulum. The patient has survived without recurrence for more than 4 years since surgery.




\section{Introduction}

Recurrent urinary tract infection (UTI) includes the possibility of discovering abnormalities such as calculi, foreign bodies, urethral diverticula, and fistulae. Recurrent UTI in men is uncommon unless associated with an underlying abnormality of the urinary tract. Vesicoenteric fistula is one cause of recurrent UTI [1]. Diverticulitis, Crohn disease, and colorectal cancer are the most common causes of vesicoenteric fistula [2]. There are several case reports of vesicoenteric fistula from a Meckel diverticulum [3-8]. We report an extremely rare case of a vesicoenteric fistula arising from an adenocarcinoma of ectopic pancreatic tissue in a Meckel diverticulum.

\section{Case Report}

A 58-year-old man visited a local medical center with a 2-week history of micturition pain and increased urinary frequency. There were no other symptoms, such as diarrhea and abdominal pain. The symptoms were resistant to antimicrobial therapy. Computerized tomography (CT) with a contrast agent for the refractory symptoms showed a ring-shaped enhanced mass $(4.0 \mathrm{~cm})$ near the dome of the urinary bladder (Fig. 1a). The patient was referred to our department for further evaluation of the lesions. His medical history showed hypertension and diabetes mellitus and the family history was unremarkable. Physical examination and routine blood tests including inflammatory reaction were unremarkable. Urine examination showed large numbers of white blood cells in urine sediment, but midstream urine culture showed no growth of bacteria after antimicrobial therapy for 2 weeks at the local medical center. Urine cytology was negative. Magnetic resonance imaging (MRI) showed a cystic mass close to the urinary bladder with a partly irregular wall and a fistula to the urinary bladder (Fig. 1b). Cystoscopy demonstrated that the fistula was near the dome of the urinary bladder, which was surrounded by edematous mucosa. Histological findings of a transurethral biopsy of the fistula and edematous mucosa showed inflammatory change with glandular metaplasia and Brunn nests of the mucosa. The preoperative diagnosis was urachal tumor, and surgery for the tumor and fistula was performed. Intraoperative findings revealed a Meckel diverticulum $(4.0 \times 3.0 \mathrm{~cm})$ at the oral side of the ileum $50 \mathrm{~cm}$ from the ileocecal junction, which was adherent to the dome of the urinary bladder. Meckel diverticulectomy and partial cystectomy were performed. Macroscopic findings of the specimen showed a tumor $(2.2 \mathrm{~cm})$ in the Meckel diverticulum with a fistula connected to the urinary bladder. Histological findings revealed a fistula arising from a papillary adenocarcinoma of ectopic pancreatic tissue in a Meckel diverticulum (Fig. 2a, b). The postoperative course was uneventful and the patient has been healthy without any evidence of disease recurrence for 4 years.

\section{Discussion}

Meckel diverticulum, which occurs in $2-4 \%$ of the population, is the most common congenital malformation of the gastrointestinal tract [9]. It is mostly asymptomatic. Clinical symptoms associated with complications of the Meckel diverticulum occur more commonly in children than adults and are rarely present in the elderly population. The complications usually arise from underlying mucosa, and include ulceration, hemorrhage, intussusception, 


\section{Case Reports in Oncology}

Fujita et al.: Vesicoenteric Fistula Arising from an Adenocarcinoma of Ectopic Pancreatic Tissue in a Meckel Diverticulum

intestinal obstruction, and perforation. Histologically, ectopic tissue is found in almost half of the Meckel diverticula. Ectopic gastric mucosa is most common (18-40\%) and causes hemorrhage associated with peptic ulceration. Ectopic pancreatic tissue is found in 5-16\% of cases $[10,11]$. The ectopic pancreas is defined as pancreatic tissue lying outside its normal location and lacking anatomic or vascular connections with the pancreas. This is usually found incidentally at laparotomy or autopsy. Neoplasms arising from ectopic pancreata are extremely rare. Guillou et al. [12] suggested that the criteria for malignant transformation of ectopic pancreas were defined as follows: (1) the tumor must be located within or very close to ectopic pancreatic tissue, (2) a direct transition between pancreatic structures and carcinoma must be observed, and (3) the non-neoplastic pancreatic tissue must have fully developed acini and ductal structures. The present case fit all the criteria. Malignant transformation in ectopic pancreas has been reported in 37 cases in the literature. These cases were located as follows: stomach (18 cases; $48.6 \%$ ), duodenum ( 7 cases, $18.9 \%$ ), jejunum ( 4 cases; $10.8 \%$ ), spleen ( 3 cases; $8.1 \%$ ), ampulla of Vater ( 2 cases; $5.4 \%$ ), hiatal hernia ( 1 case; $2.7 \%$ ), distal esophagus ( 1 case; $2.7 \%$ ), and Meckel diverticulum (1 case; $2.7 \%$ ). Preoperative diagnosis of ectopic pancreas malignancy may be difficult with imaging studies. The prognosis of adenocarcinoma arising from ectopic pancreas is not clear [13-20]. However, the prognosis may be better than that of primary pancreatic carcinoma, probably due to the earlier clinical presentation of the carcinoma in ectopic pancreas [21].

Vesicoenteric fistulae most commonly occur secondary to diverticulitis, Crohn disease, or colorectal cancer [2]. Six cases of intestinal fistula complicated by perforation of the Meckel diverticulum are reported in the English literature. The causes of these cases were as follows: no coexisting bowel or bladder disease ( 2 patients), bladder calculi ( 1 patient), Crohn ileitis (1 patient), enterolith (1 patient), and ingested foreign body in the Meckel diverticulum ( 1 patient). As regards the 5 cases, in preoperative imaging tests for the diagnosis of the vesicoenteric fistulae, CT, MRI, and cystography were performed in 2 cases, 1 case, and 2 cases, respectively [3-8]. In an imaging study of vesicoenteric fistulae, Golabek et al. [22] reported that the detection rates for vesicoenteric fistulae of CT, MRI, and cystography were 90-100, 100 and 20-30\%, respectively, and cross-sectional imaging with CT and MRI may be an ideal modality option in patients with vesicoenteric fistulae. The imaging test is effective for the diagnosis of vesicoenteric fistulae, but pathological examination in surgery is necessary for information on the cause.

In summary, to our knowledge, we report the first case of vesicoenteric fistula arising from an adenocarcinoma of ectopic pancreatic tissue in a Meckel diverticulum. Although complications of Meckel diverticulum are not common, the possibility of this scenario should be considered when faced with vesicoenteric fistulae.

\section{Statement of Ethics}

The patient gave written informed consent.

\section{Disclosure Statement}

The authors have no conflicts of interest to declare. 
Fujita et al.: Vesicoenteric Fistula Arising from an Adenocarcinoma of Ectopic Pancreatic Tissue in a Meckel Diverticulum

\section{References}

1 Schaeffer A: Infection of the urinary tract; in Peters C, Partin A, Kavoussi L, Wein A (eds): CampbellWalsh Urology, 11th Edition. Philadelphia, Saunders, 2016, pp 237-303.

2 Karamchandani MC, West CF Jr: Vesicoenteric fistulas. Am J Surg 1984;147:681-683.

3 Dearden C, Humphreys WG: Meckel's diverticulum: a vesico-diverticular fistula. Ulster Med J 1983;52:73-74.

4 MacKenzie TM, Kisner CD, Murray J: Vesicoileal fistula via Meckel diverticulum. Urology 1989;33:475476.

5 Petros JG, Argy 0: Enterovesical fistula from Meckel's diverticulum in a patient with Crohn's ileitis. Dig Dis Sci 1990;35:133-136.

6 Hudson HM 2nd, Millham FH, Dennis R: Vesico-diverticular fistula: a rare complication of Meckel's diverticulum. Am Surg 1992;58:784-786.

7 Graziotti P, Maffezzini M, Candiano G, Maugeri O: Vesicoenteric fistula created by ingested foreign body in Meckel's diverticulum. J Urol 2002;168:2547.

8 Bouassida M, Mighri MM, Trigui K, Chtourou MF, Sassi S, Feidi B, Chebbi F, Bouzaidi K, Touinsi H, Sassi S: Meckel's diverticulum: an exceptional cause of vesicoenteric fistula: case report and literature review. Pan Afr Med J 2013;15:9.

9 Sagar J, Kumar V, Shah DK: Meckel's diverticulum: a systematic review. J R Soc Med 2006;99:501-505.

10 Levy AD, Hobbs CM: From the archives of the AFIP: Meckel diverticulum: radiologic features with pathologic correlations. Radiographics 2004;24:565-587.

11 Yahchouchy EK, Marano AF, Etienne JC, Fingerhut AL: Meckel's diverticulum. J Am Coll Surg 2001;192:658-662.

12 Guillou L, Nordback P, Gerber C, Schneider RP: Ductal adenocarcinoma arising in a heterotopic pancreas situated in a hiatal hernia. Arch Pathol Lab Med 1994;118:568-571.

13 Goodarzi M, Rashid A, Maru D: Invasive ductal adenocarcinoma arising from pancreatic heterotopia in rectum: case report and review of literature. Hum Pathol 2010;41:1809-1813.

14 Koh HC, Page B, Black C, Brown I, Ballantyne S, Galloway DJ: Ectopic pancreatic-type malignancy presenting in a Meckel's diverticulum: a case report and review of the literature. World J Surg Oncol 2009;7:54.

15 Bini R, Voghera P, Tapparo A, Nunziata R, Demarchi A, Capocefalo M, Leli R: Malignant transformation of ectopic pancreatic cells in the duodenal wall. World J Gastroenterol 2010;16:1293-1295.

16 Okamoto H, Kawaoi A, Ogawara T, Fujii H: Invasive ductal carcinoma arising from an ectopic pancreas in the gastric wall: a long-term survival case. Case Rep Oncol 2012;5:69-73.

17 Kinoshita H, Yamaguchi S, Shimizu A, Sakata Y, Arii K, Mori K, Nasu T: Adenocarcinoma arising from heterotopic pancreas in the duodenum. Int Surg 2012;97:351-355.

18 Ginori A, Vassallo L, Butorano MA, Bettarini F, Di Mare G, Marrelli D: Pancreatic adenocarcinoma in duodenal ectopic pancreas: a case report and review of the literature. Pathologica 2013;105:56-58.

19 Lemaire J, Delaunoit T, Molle G: Adenocarcinoma arising in gastric heterotopic pancreas. Case report and review of the literature. Acta Chir Belg 2014;114:79-81.

20 Fukino N, Oida T, Mimatsu K, Kuboi Y, Kida K: Adenocarcinoma arising from heterotopic pancreas at the third portion of the duodenum. World J Gastroenterol 2015;21:4082-4088.

21 Eisenberger CF, Gocht A, Knoefel WT, Busch CB, Peiper M, Kutup A, Yekebas EF, Hosch SB, Lambrecht W, Izbicki JR: Heterotopic pancreas - Clinical presentation and pathology with review of the literature. Hepatogastroenterology 2004;51:854-858.

22 Golabek T, Szymanska A, Szopinski T, Bukowczan J, Furmanek M, Powroznik J, Chlosta P: Enterovesical fistulae: aetiology, imaging, and management. Gastroenterol Res Pract 2013;2013:617967. 


\section{Case Reports in Oncology}

Case Rep Oncol 2018;11:6-10
\begin{tabular}{l|l}
\hline DOI: 10.1159/000485458 & $\begin{array}{l}\text { (c) 2018 The Author(s). Published by S. Karger AG, Basel } \\
\text { www.karger.com/cro }\end{array}$ \\
\hline
\end{tabular}

Fujita et al.: Vesicoenteric Fistula Arising from an Adenocarcinoma of Ectopic Pancreatic Tissue in a Meckel Diverticulum
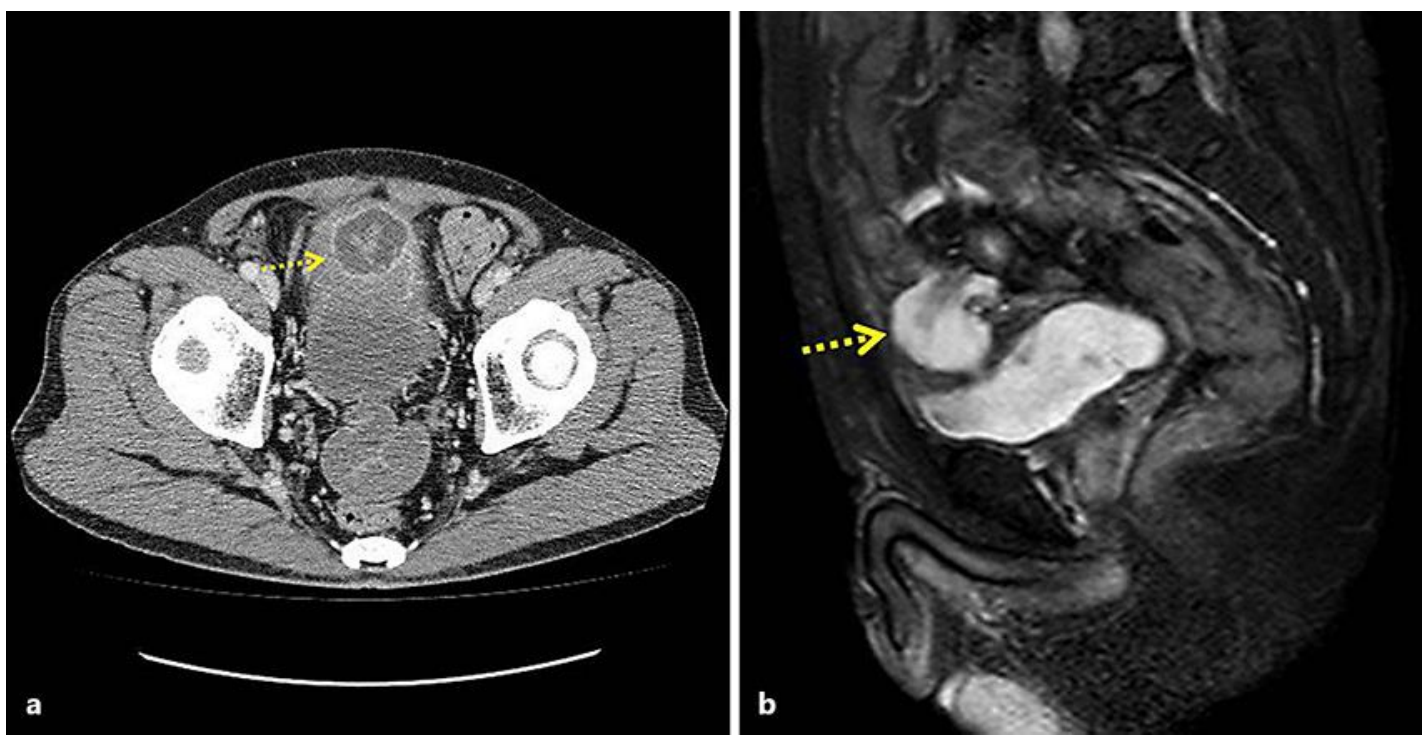

Fig. 1. Preoperative radiological findings. a Pelvic contrast-enhanced CT showed a ring-shaped enhanced mass near the dome of the urinary bladder (yellow dotted line). b Pelvic T2-weighted MRI (sagittal section) showed a cystic mass with a partly irregular wall and fistula formation to the urinary bladder (yellow dotted line).

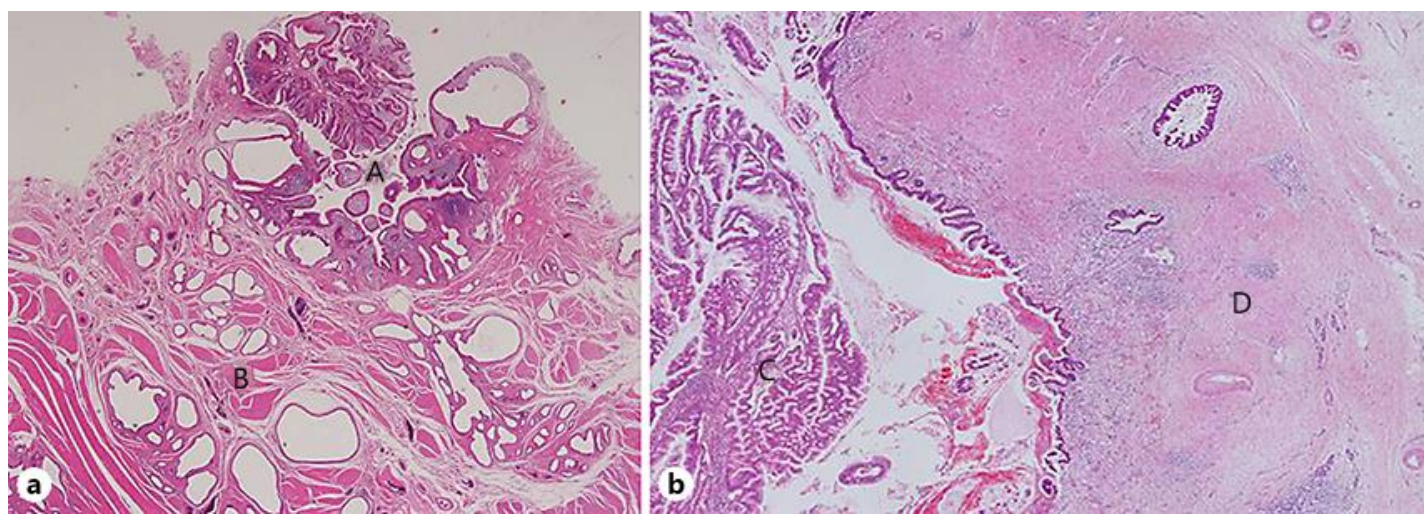

Fig. 2. Histological findings. a Meckel diverticulum (A) and ectopic pancreatic tissue (B). HE. $\times 25$. b Adenocarcinoma arising from the ectopic pancreatic tissue (C) and ectopic pancreatic tissue (D). HE. $\times 100$. 